\title{
Additional Evidence for the Long-Term Benefits of Pulmonary Rehabilitation
}

\author{
DorAnne Donesky PhD ANP-BC, Tracie L Citron MSc CNS, \\ Lana Hilling, Cindy Cayou, and Michelle M Milic MD
}

\begin{abstract}
BACKGROUND: Pulmonary rehabilitation programs document outcomes to prepare for program certification, to demonstrate the value of the program to upper management, and to provide feedback to pulmonary rehabilitation staff regarding the efficacy of the program. The overall goal of this study was to evaluate the feasibility of using non-research-generated clinical data to report long-term outcomes following a pulmonary rehabilitation program. METHODS: Using a longitudinal descriptive design, all subjects who completed pulmonary rehabilitation at one communitybased pulmonary rehabilitation program in the San Francisco Bay Area were asked to complete a 6-month and subsequent yearly questionnaires. Adherence to pulmonary rehabilitation techniques was described for $\mathbf{7} \mathbf{y}$ following pulmonary rehabilitation participation, health-care utilization from $1 \mathrm{y}$ before pulmonary rehabilitation was compared with subsequent years, and health-care utilization was compared between those who participated in ongoing regular exercise after pulmonary rehabilitation and those who did not exercise. RESULTS: More than 70\% of subjects who completed the questionnaire reported adherence to pulmonary rehabilitation techniques, including exercise for at least $\mathbf{7 y}$ following pulmonary rehabilitation. Health-care utilization declined after pulmonary rehabilitation. Subjects who did not exercise regularly required significantly more health care than those who exercised regularly $(P<.05)$. CONCLUSIONS: This study demonstrated the ability of one pulmonary rehabilitation program to accurately monitor extended longterm follow-up after pulmonary rehabilitation. Implementing this long-term monitoring methodology consistently in pulmonary rehabilitation programs could contribute to evaluation of the comparative effectiveness of various treatment options. Key words: lung diseases; obstructive; pulmonary disease; chronic obstructive; pulmonary rehabilitation; health-care utilization; exercise; longterm follow-up. [Respir Care 2015;60(8):1120-1129. (C) 2015 Daedalus Enterprises]
\end{abstract}

\section{Introduction}

Pulmonary rehabilitation is well established as the standard of care for patients with symptomatic chronic pul-

\footnotetext{
Dr Donesky is affiliated with the Department of Physiological Nursing, University of California, San Francisco, California. Ms Citron is affiliated with the San Francisco Department of Veterans Affairs Medical Center, San Francisco, California. Ms Hilling and Ms Cayou are affiliated with the Pulmonary Rehabilitation Program, John Muir Health, Concord, California. Dr Milic is affiliated with the Pulmonary Division, Georgetown University, Washington, DC.
}

Supplementary material related to this paper is available at http:// www.rcjournal.com.

This study was supported in part by the University of California, San monary disease..$^{1,2}$ However, after an intensive 6-12-week pulmonary rehabilitation program, the benefits of pulmonary rehabilitation gradually decline over time. ${ }^{3-7}$ Two multi-site, community-based collaborative groups, one in

\footnotetext{
Francisco School of Nursing Intramural Research Fund. The authors have disclosed no conflicts of interest.

Dr Donesky presented a version of this paper at the 2010 International Conference of the American Thoracic Society, held May 14-19, 2010, in New Orleans, Louisiana.
}

Correspondence: DorAnne Donesky PhD ANP-BC, Department of Physiological Nursing, University of California, Box 0610, San Francisco, CA 94143-0610. E-mail: doranne.donesky@ucsf.edu.

DOI: $10.4187 /$ respcare.03153 


\section{Long-Term Benefits of Pulmonary Rehabilitation}

the Northeastern United States and one in California, collected data and reported outcomes in an effort to document the value of pulmonary rehabilitation over time outside the academic research environment. ${ }^{9}$ In the Northeast group, a significant reduction in hospitalizations 12 months after pulmonary rehabilitation was documented in 128 subjects from 11 hospital-based programs. ${ }^{8,9}$ The California Pulmonary Rehabilitation Collaborative Group consisted of 9 pulmonary rehabilitation centers in California that followed 521 subjects for 18 months after participation in a pulmonary rehabilitation program. ${ }^{8}$ They documented spirometry and 6-min walk distances at baseline, as well as quality of life, shortness of breath, and health-care utilization questionnaires at baseline and at 3, 6, 12, and 18 months following pulmonary rehabilitation. There were significant and consistent improvements in symptoms and quality of life immediately after pulmonary rehabilitation, which declined with time; however, these outcomes were still above pre-rehabilitation levels at 18 months.

Although the California Pulmonary Rehabilitation Collaborative Group disbanded after 18 months, ${ }^{8}$ staff at one pulmonary rehabilitation program continued collecting yearly long-term follow-up data on their subjects. As part of a quality improvement project to document outcomes for hospital administration and support their program certification, they were interested in documenting the patterns of hospitalizations and emergency department visits and determining whether subjects continued to practice the skills taught in pulmonary rehabilitation: exercise, pursedlip breathing, energy conservation, contact with the healthcare provider's office at the first sign of an exacerbation, and support group participation. With no paid staff dedicated to the project, no budget, and no research background, the staff designed and implemented an annual questionnaire focusing on clinically relevant issues. The goal of data collection was to justify the value of the program to administrators, generate long-term quality improvement data, and compare the long-term outcomes of this community-based pulmonary rehabilitation program with published pulmonary rehabilitation outcome data.

The overall objective of this study was to evaluate the value of using non-research-generated clinical data to report long-term outcomes following a pulmonary rehabilitation program. Specifically, the purpose was to (1) describe health status and adherence to pulmonary rehabilitation techniques in the years following pulmonary rehabilitation participation, (2) compare health-care utilization $1 \mathrm{y}$ before pulmonary rehabilitation with subsequent years, and (3) determine the impact of ongoing regular exercise after pulmonary rehabilitation on health-care utilization. We hypothesized that emergency department visits, hospitalizations, and length of stay would decrease after pulmonary rehabilitation and that ongoing regular exercise after pulmonary rehabilitation would be associ-

\section{QUICK LOOK}

\section{Current knowledge}

Pulmonary rehabilitation is a comprehensive program of education, exercise, and therapeutic treatment aimed at reducing symptoms and improving quality of life in patients with chronic lung disease. The impact of pulmonary rehabilitation appears to wane over time with progression of disease, and the costs associated with rehabilitation are frequently debated.

\section{What this paper contributes to our knowledge}

Participation in a pulmonary rehabilitation program decreased health-care utilization for at least $7 \mathrm{y}$ following participation. These subjects had fewer emergency department visits and required fewer hospitalizations over an extended time frame. Subjects who consistently exercised had lower health-care utilization, which could be related to techniques learned in the program.

ated with lower health-care utilization. A secondary aim was to compare the demographic data of subjects who completed at least one follow-up questionnaire with those who did not complete any questionnaires.

\section{Methods}

Using a longitudinal descriptive design, all subjects who completed pulmonary rehabilitation at one communitybased pulmonary rehabilitation program in the San Francisco Bay Area were asked to complete a 6-month and subsequent yearly questionnaires. Institutional review board approval for this study was obtained from both the community hospital and the university.

\section{Sample and Procedure}

Beginning in 2004, every subject who completed outpatient pulmonary rehabilitation at the participating program was mailed a questionnaire at 6 months, $1 \mathrm{y}$, and yearly thereafter. This analysis included data collected between 2004 and 2010 from subjects who responded to at least one follow-up questionnaire and graduated between 2000 and 2009. Inclusion criteria included anyone who completed pulmonary rehabilitation at the participating program. The following requirements were necessary for participation in pulmonary rehabilitation: a physical examination within the previous $90 \mathrm{~d}$ indicating ability to participate in the plan of care; willingness to either quit smoking or participate in smoking cessation activities before or during pulmonary rehabilitation; significant im- 
pairment of functioning by disabling symptoms; and pulmonary function tests revealing $\mathrm{FVC}, \mathrm{FEV}_{1}$, or diffusing capacity of the lung for carbon monoxide of $<65 \%$ within $1 \mathrm{y}$ before initiating pulmonary rehabilitation.

The pulmonary rehabilitation program consisted of 6 weeks of supervised exercise training; education on topics such as lung physiology, breathing retraining, energy conservation, pulmonary medications, home exercise, and management of exacerbations; support groups for discussion of depression, anxiety, and frustration; and stress management and relaxation techniques. Subjects were encouraged to continue to exercise after completing pulmonary rehabilitation, and this pulmonary rehabilitation program included an active maintenance exercise program.

Demographics were not reported on the yearly questionnaires but were available for subjects who completed questionnaires after 2007. To determine the secondary aim regarding the difference between subjects who returned questionnaires and those who did not, we divided the available demographic data set into 2 groups based on availability of at least one follow-up questionnaire.

\section{Questionnaire}

The follow-up questionnaire was developed by the pulmonary rehabilitation director based on clinical judgment and experience. Eighteen questions were designed to solicit information on recent emergency department visits and hospitalizations, current health and smoking status, adherence to strategies taught in pulmonary rehabilitation (such as early medical contact at first signs of exacerbation, pursed-lip breathing, and energy conservation), ongoing attendance at the monthly support group, and exercise participation. A COPD exacerbation was defined as an acute worsening of symptoms, including cough, change in sputum quantity, or quality and worsening of shortness of breath requiring a modification of medical therapy and possible hospitalization. ${ }^{10}$ Additional details were solicited regarding barriers to exercise and barriers to attendance at the monthly support group. The questionnaire collected information on the number of times/week subjects performed maintenance exercise, whether they exercised at home or elsewhere, and frequency of exercise/ week and duration of exercise/d. In addition, the initial follow-up questionnaire inquired about emergency visits and hospitalizations during the year before attending pulmonary rehabilitation (for a copy of the questionnaire, see Appendix A in the supplementary materials at http:// www.rcjournal.com).

\section{Statistical Analysis}

Descriptive statistics including means $\pm \mathrm{SD}$ for continuous variables and frequencies for categorical variables were generated using SPSS 18 (SPSS, Chicago, Illinois). Baseline demographic characteristics were compared between subjects who completed at least one questionnaire and those who did not complete any follow-up questionnaires using 2-tailed $t$ tests for continuous variables and chi-square test for categorical variables. $P<.05$ was taken to indicate significance.

The percentage of subjects who reported one or more emergency department visits or one or more hospitalizations was calculated at each yearly time point, and that percentage was compared with the percentage of subjects who reported one or more emergency department visits or hospitalization in the year before attending pulmonary rehabilitation using paired-sample 2-tailed $t$ tests. For those subjects who reported at least one emergency department visit or hospitalization, we calculated the average number of emergency department visits and the average number of hospital days in the previous year and compared those averages with the average emergency department visits or hospitalizations reported in the year before attending pulmonary rehabilitation using paired-sample $t$ tests.

We identified subjects who self-reported an average of one or more exercise sessions/week at each time period, whether at home, in a gym, in the pulmonary rehabilitation facility, or at any other location, and dichotomized the sample as one or more sessions compared with zero exercise sessions/week. We calculated the percentage of subjects in each of the 2 exercise groups (exercise at least $1 \mathrm{~d} /$ week vs no exercise) who had at least one emergency department visit or hospitalization during each yearly time period, and we compared the percentage of subjects with at least one health-care utilization event between the 2 exercise groups using chi-square tests. We then selected subjects who had at least one emergency department visit or one hospitalization at each time point, and we compared the mean number of emergency department visits or hospital days in each exercise group using independentsample $t$ tests.

\section{Results}

\section{Sample}

A total of 1,006 subjects completed the pulmonary rehabilitation program between 2000 and 2009. Of these subjects, 755 returned at least one follow-up questionnaire and are included in this analysis. Demographic data were available for 224 subjects who completed pulmonary rehabilitation between 2007 and 2009 and completed at least one follow-up questionnaire. As shown in Table 1, the mean age was $71 \pm 10 \mathrm{y}$, two thirds of the sample were women, approximately half were married, and the majority $(\sim 85 \%)$ had moderate-to-severe COPD. The remaining 
Table 1. Baseline Subject Characteristics and Questionnaire Adherence (2007-2009)

\begin{tabular}{|c|c|c|c|c|}
\hline Variable & $\begin{array}{l}\text { All Subjects } \\
(n=327)\end{array}$ & $\begin{array}{l}\text { Completed } \\
\text { Questionnaire } \\
(n=224)\end{array}$ & $\begin{array}{c}\text { Did Not Complete } \\
\text { Questionnaire } \\
(n=103)\end{array}$ & $P$ \\
\hline Age (mean $\pm \mathrm{SD}), \mathrm{y}$ & $70 \pm 10$ & $71 \pm 10$ & $69 \pm 12$ & .18 \\
\hline Female, $\%$ & 60 & 61 & 56 & .41 \\
\hline Married, \% & 53 & 51 & 59 & .18 \\
\hline GOLD COPD & & & & .02 \\
\hline Mild, \% & 25 & 23 & 28 & \\
\hline Moderate, $\%$ & 40 & 45 & 28 & \\
\hline Severe, $\%$ & 27 & 25 & 29 & \\
\hline Very severe, $\%$ & 9 & 6 & 16 & \\
\hline $\mathrm{FEV}_{1}($ mean $\pm \mathrm{SD}), \%$ predicted $\uparrow$ & $62.5 \pm 24.1$ & $64.1 \pm 23.9$ & $58.7 \pm 24.2$ & .09 \\
\hline FVC $($ mean $\pm \mathrm{SD}), \%$ predicted $\uparrow$ & $80.5 \pm 43.3$ & $78.4 \pm 22.1$ & $85.3 \pm 71.9$ & .23 \\
\hline 6MWD baseline (mean $\pm \mathrm{SD}$ ), $\mathrm{m} \uparrow$ & $300.0 \pm 125.2$ & $318.8 \pm 124.1$ & $257.4 \pm 117.6$ & $<.001$ \\
\hline Dyspnea during 6MWT (mean $\pm \mathrm{SD}) \downarrow$ & $3.2 \pm 1.6$ & $3.2 \pm 1.6$ & $3.3 \pm 1.5$ & .74 \\
\hline CES-D (mean \pm SD) $\downarrow$ & $15.1 \pm 9.8$ & $14.2 \pm 9.3$ & $17.2 \pm 10.5$ & .01 \\
\hline SOBQ $($ mean $\pm \mathrm{SD}) \downarrow$ & $52.1 \pm 23.0$ & $48.8 \pm 23.0$ & $58.9 \pm 21.8$ & $<.001$ \\
\hline Current smoker, \%* & & 6.4 & & \\
\hline \multicolumn{5}{|c|}{$\begin{array}{l}\text { Arrows indicate preferred scores. } \\
* \text { Data on smoking status were available only for subjects who completed the questionnaires. } \\
\text { GOLD }=\text { Global Initiative for Chronic Obstructive Lung Disease } \\
\text { 6MWD }=6 \text {-min walk distance } \\
\text { 6MWT }=6 \text {-min walk test } \\
\text { CES-D }=\text { Center for Epidemiologic Studies Depression Scale } \\
\text { SOBQ }=\text { University of California, San Diego Shortness of Breath Questionnaire }\end{array}$} \\
\hline
\end{tabular}

subjects had restrictive lung disease, mostly interstitial lung disease, diaphragm dysfunction, or post lung cancer.

\section{Health Status and Adherence to Pulmonary Rehabilitation Techniques}

Approximately two thirds of the subjects reported improvement in their general health status for the first $3 \mathrm{y}$ following pulmonary rehabilitation, and $>50 \%$ continued to report improved health throughout the $7 \mathrm{y}$ of follow-up.

Adherence to the principles of pulmonary rehabilitation was evaluated using 5 commonly taught techniques: (1) ongoing exercise, (2) pursed-lip breathing, (3) energy conservation, (4) contact with health-care provider's office, and (5) support group participation. Two thirds of the subjects $(68-72 \%)$ reported regular ongoing exercise, averaging 3.4-3.9 $\mathrm{d} /$ week and $27-32 \mathrm{~min} /$ session, during the $7 \mathrm{y}$ of follow-up. Of these, more than one third consistently attended maintenance exercise for an average of 2.3-2.5 d/week (Table 2).

More than $89 \%$ of subjects who completed the questionnaire reported using pursed-lip breathing and energy conservation for $>7 \mathrm{y}$ following pulmonary rehabilitation. Seventy percent of subjects reported calling their health-care provider at the first sign of an exacerbation for the duration of the study.

Less than $10 \%$ of subjects attended the monthly support groups. The most common reasons for not attending were: transportation/location/distance ( $20 \%$ at $6 \mathrm{mo})$, unaware of the meeting (19\% at $6 \mathrm{mo})$, not interested $(15 \%$ at $6 \mathrm{mo})$, and scheduling conflicts (10\% at $6 \mathrm{mo})$. Other less common reasons included: poor health and forgetfulness (5\% each). These reasons and percentages were consistent over the course of the follow-up period.

\section{Health-Care Utilization Before and After Pulmonary Rehabilitation}

Significant declines in the percentage of subjects who utilized health care (emergency department visits or hospitalizations) were documented at $1 \mathrm{y}$ following pulmonary rehabilitation (emergency department visits: $26.6 \%$ before pulmonary rehabilitation and $8.9 \%$ at $1 \mathrm{y}, P<.001$; hospitalizations: $28.5 \%$ before pulmonary rehabilitation and $10.2 \%$ at $1 \mathrm{y}, P<.001)$ and subsequently continued for $7 \mathrm{y}$ compared with health-care utilization before pulmonary rehabilitation participation (Fig. 1). For subjects who had at least one emergency department visit, there was a significant decline in the average number of emergency department visits at $1 \mathrm{y}(1.8 \pm 1.3$ emergency department visits before pulmonary rehabilitation and $1.3 \pm 0.6$ emergency department visits at $1 \mathrm{y}, P=.01$ ) but stayed the same during all subsequent years. Similarly, the mean hospital stay remained the same after pulmonary rehabilitation at all follow-up times for those who had at least one hospitalization. 
Table 2. Outcomes After Pulmonary Rehabilitation

\begin{tabular}{|c|c|c|c|c|c|c|c|c|}
\hline Variable & $\begin{array}{c}6 \text { mo } \\
(n=424)\end{array}$ & $\begin{array}{c}1 \mathrm{y} \\
(n=390)\end{array}$ & $\begin{array}{c}2 \mathrm{y} \\
(n=292)\end{array}$ & $\begin{array}{c}3 \mathrm{y} \\
(n=268)\end{array}$ & $\begin{array}{c}4 \mathrm{y} \\
(n=198)\end{array}$ & $\begin{array}{c}5 \mathrm{y} \\
(n=108)\end{array}$ & $\begin{array}{c}6 \mathrm{y} \\
(n=83)\end{array}$ & $\begin{array}{c}7 \mathrm{y} \\
(n=53)\end{array}$ \\
\hline \multicolumn{9}{|l|}{ Exercise } \\
\hline Regular ongoing exercise, $\%$ & 72 & 71 & 70 & 67 & 69 & 70 & 68 & 68 \\
\hline $\mathrm{d} / \mathrm{wk}($ mean $\pm \mathrm{SD})$ & $3.9 \pm 1.7$ & $3.7 \pm 1.7$ & $3.7 \pm 1.7$ & $3.6 \pm 1.7$ & $3.8 \pm 1.8$ & $3.8 \pm 1.7$ & $3.4 \pm 1.5$ & $3.4 \pm 1.6$ \\
\hline $\min / \mathrm{d}($ mean $\pm \mathrm{SD})$ & $31 \pm 19$ & $32 \pm 18$ & $32 \pm 18$ & $32 \pm 20$ & $29 \pm 16$ & $27 \pm 17$ & $30 \pm 17$ & $29 \pm 23$ \\
\hline Maintenance exercise, $\%$ & 47 & 42 & 37 & 39 & 37 & 34 & 33 & 30 \\
\hline $\mathrm{d} / \mathrm{wk}($ mean $\pm \mathrm{SD})$ & $2.5 \pm 0.7$ & $2.4 \pm 0.7$ & $2.4 \pm 0.6$ & $2.4 \pm 0.6$ & $2.4 \pm 0.7$ & $2.4 \pm 0.7$ & $2.3 \pm 0.7$ & $2.3 \pm 0.7$ \\
\hline \multicolumn{9}{|l|}{ Other pulmonary rehabilitation techniques, $\%$} \\
\hline Pursed-lip breathing & 95 & 94 & 93 & 96 & 95 & 89 & 95 & 98 \\
\hline Energy conservation & 97 & 96 & 95 & 96 & 98 & 96 & 98 & 96 \\
\hline Contact with health-care provider's office & 69 & 70 & 69 & 73 & 73 & 75 & 76 & 77 \\
\hline Support group participation & 8 & 6 & 9 & 7 & 7 & 8 & 8 & 6 \\
\hline
\end{tabular}

\section{Impact of Regular Exercise on Health-Care Utilization}

To distinguish the effect of self-reported regular exercise after pulmonary rehabilitation on health-care utilization, we compared health-care utilization by those who exercised regularly, either during maintenance exercise at the pulmonary rehabilitation facility or elsewhere, with those who did not (Table 3). Subjects who did not exercise experienced significantly more emergency department visits at 1 and 6 y compared with those who exercised regularly. Subjects who did not exercise experienced significantly more hospitalizations than those who exercised regularly at 1 and $2 \mathrm{y}$. Of those who experienced at least one emergency department visit or hospitalization, there was no significant difference in the number of emergency department visits/y (1.3-2.2 visits/y through 5 y) or length

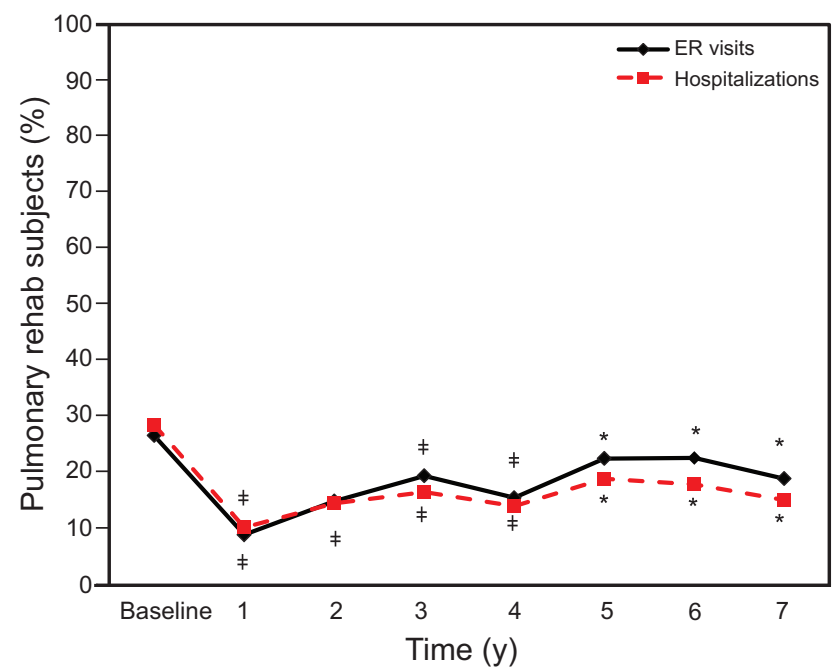

Fig. 1. Percentage of pulmonary rehabilitation subjects with at least one health-care utilization contact in the previous year. $\mathrm{ER}=$ emergency room. ${ }^{*} P<.05 ; \ddagger P<.001$. of hospital stay (5-14.7 d/y through $5 \mathrm{y}$ ) between those who exercised regularly and those who did not exercise.

\section{Questionnaire Adherence}

In comparison with those who did not complete any follow-up questionnaires, subjects who completed at least one questionnaire walked farther during their baseline 6-min walk test $(P<.001)$ and reported fewer depressive symptoms $(P=.01)$ and less shortness of breath $(P<.001)$ (see Table 1). Those who completed the questionnaires also had less severe COPD according to the criteria of the Global Initiative for Chronic Obstructive Lung Disease $(P=.02)$.

\section{Discussion}

The majority of subjects who completed pulmonary rehabilitation in this longitudinal descriptive study continued to practice non-pharmacologic techniques, including ongoing exercise participation, pursed-lip breathing, and energy conservation, whereas findings were mixed with respect to calling the health-care provider at the first sign of an exacerbation and support group participation. Continuing to exercise after pulmonary rehabilitation at either the pulmonary rehabilitation facility or another location, was significantly associated with decreased health-care utilization. One unique contribution of this study was the collaboration between the community-based clinicians, who collected the quality improvement data, and the university researchers, who analyzed the data. This study demonstrated that it is possible to collect quality improvement data that are valuable for research purposes with a standardized protocol that minimizes burden to both subjects and clinicians. 
Table 3. HCU Comparison Between Subjects Who Exercised Regularly and Those Who Did Not

\begin{tabular}{|c|c|c|c|c|c|c|c|}
\hline Variable & $\begin{array}{c}1-y \\
\text { Follow-up } \\
(324 / 69)^{*}\end{array}$ & $\begin{array}{c}2-y \\
\text { Follow-up } \\
(232 / 64)\end{array}$ & $\begin{array}{c}3-y \\
\text { Follow-up } \\
(213 / 60)\end{array}$ & $\begin{array}{c}4-y \\
\text { Follow-up } \\
(157 / 42)\end{array}$ & $\begin{array}{c}5-y \\
\text { Follow-up } \\
(84 / 26)\end{array}$ & $\begin{array}{c}6-y \\
\text { Follow-up } \\
(66 / 18)\end{array}$ & $\begin{array}{c}\text { 7-y } \\
\text { Follow-up } \\
\text { (40/13) }\end{array}$ \\
\hline \multicolumn{8}{|c|}{ Subjects with at least one HCU contact, \% } \\
\hline \multicolumn{8}{|l|}{ ER visits } \\
\hline Regular exercise (1 time/wk) & 7.1 & 13.8 & 18.3 & 15.9 & 20.2 & 16.7 & 17.5 \\
\hline No exercise & 17.4 & 18.8 & 23.3 & 14.3 & 30.8 & 44.4 & 23.1 \\
\hline$P$ & .01 & .32 & .39 & .80 & .26 & .01 & .66 \\
\hline \multicolumn{8}{|l|}{ Hospitalizations } \\
\hline Regular exercise (1 time/wk) & 8.6 & 11.6 & 16.0 & 15.3 & 17.9 & 16.7 & 17.5 \\
\hline No exercise & 17.4 & 25.0 & 18.3 & 9.5 & 23.1 & 22.2 & 7.7 \\
\hline$P$ & .03 & .01 & .66 & .34 & .55 & .59 & .39 \\
\hline \multicolumn{8}{|c|}{$\begin{array}{l}\text { No. of HCU contacts for subjects with } \\
\text { at least one HCU contact (mean } \pm \mathrm{SD} \text { ) }\end{array}$} \\
\hline \multicolumn{8}{|l|}{ ER visits } \\
\hline Regular exercise (1 time/wk) & $1.3 \pm 0.5$ & $1.4 \pm 0.6$ & $1.6 \pm 0.9$ & $2.2 \pm 1.6$ & $1.1 \pm 0.3$ & $13 \pm 23$ & $1.3 \pm 0.5$ \\
\hline No exercise & $1.3 \pm 0.6$ & $1.6 \pm 1.2$ & $1.9 \pm 0.9$ & $1.8 \pm 1.0$ & $1.4 \pm 1.1$ & $7.8 \pm 6.1$ & $1.7 \pm 1.2$ \\
\hline$P$ & .75 & .59 & .22 & .44 & .52 & .50 & .63 \\
\hline \multicolumn{8}{|l|}{ Hospital days } \\
\hline Regular exercise (1 time/wk) & $10 \pm 13.9$ & $5.7 \pm 3.8$ & $14.7 \pm 34.7$ & $12.1 \pm 16.6$ & $14.2 \pm 20.0$ & $1.5 \pm 0.9$ & $6 \pm 2.1$ \\
\hline No exercise & $8.2 \pm 9.2$ & $9.6 \pm 13.1$ & $9.2 \pm 6.7$ & $5 \pm 0.8$ & $4.5 \pm 2.6$ & $1.6 \pm 0.7$ & 16 (one subject) \\
\hline$P$ & .63 & .26 & .40 & .05 & .09 & .66 & .01 \\
\hline
\end{tabular}

\section{Long-Term Exercise Adherence}

Exercise is the component of pulmonary rehabilitation that consistently demonstrates the most improvement in patient health outcomes. ${ }^{2}$ Providing guidelines for exercise and long-term self-management strategies to promote exercise so patients can continue to experience the benefits of exercise over the long term is a high priority for pulmonary rehabilitation clinicians. ${ }^{11}$ Although a pulmonary rehabilitation program involves a group setting, the patients receive individualized attention, which is critical to managing dyspnea and reducing the anxiety often associated with dyspnea. ${ }^{12}$

During the course of a pulmonary rehabilitation program, patients are encouraged to increase both the endurance and intensity of exercise and create an exercise routine that will continue to support their health and quality of life after the pulmonary rehabilitation program concludes. The exercise program is promoted as a lifestyle change to continue indefinitely. As with pharmacologic studies in which the subject's perceived benefit of treatment is recognized to affect the subject's decision to continue or discontinue treatment, ${ }^{13}$ those who experience more immediate health benefits may be more likely to continue exercise after pulmonary rehabilitation.

Similar to our previously published findings, ${ }^{14}$ subjects who exercised regularly after pulmonary rehabilitation maintained a stable duration of $25-30 \mathrm{~min} / \mathrm{session}$, but the frequency (d/week) declined over time. This reinforces the importance of encouraging patients to maintain their commitment to a regular exercise schedule. Once they start the exercise session, they are likely to continue for the full duration. In addition, when maintenance exercise is available on multiple days/week, patients are able to come to the pulmonary rehabilitation facility for all of their exercise sessions and are not required to overcome the additional barrier of developing another exercise routine at a different location.

Given that our data support ongoing exercise regardless of venue, the first priority must be to reinforce the importance of long-term, ongoing exercise in this patient population. The decision about whether maintenance exercise at the pulmonary rehabilitation facility is the best option or whether another venue is preferable is a very personal decision based on many factors, such as disease severity, emotional status, occupational status, transportation, and living situation.

\section{Pursed-Lip Breathing Techniques}

Pursed-lip breathing has been shown to be effective in the short term by controlling panic and decreasing breathing frequency and anxiety. It is well accepted as a valuable therapy to counteract shortness of breath in patients with chronic lung disease. ${ }^{15}$ Our findings support the value of pursed-lip breathing with high adherence rates for up to 
7 y after participation in pulmonary rehabilitation (8896\%). Pursed-lip breathing is readily available, does not require expensive equipment, and can be easily implemented during activity. ${ }^{16}$ Although there is no standard pursed-lip breathing training technique and the focus of those who teach pursed-lip breathing may be on back pressures, expiratory flow, oxygen saturation, or residual volume, patients still report significant benefit and continue to use pursed-lip breathing. Perhaps additional investigation and measurement of pressure, volume, timing, gas exchange, and activity could clarify the pulmonary mechanics related to benefits. ${ }^{17}$

Given the clinical benefits of pursed-lip breathing in both symptoms and gas exchange, especially in combination with oximetry-based biofeedback, research evidence supports recommendations that patients with chronic respiratory disease use these training techniques. ${ }^{17,18}$ Focus on a counted breathing pattern during pursed-lip breathing may attain benefits similar to visualization and relaxation techniques. Pursed-lip breathing helps patients avoid and alleviate dyspnea and maintain control of breathing.

\section{Energy Conservation Strategies}

Although pacing and energy conservation are well accepted as part of clinical practice and have been tested in lung cancer, ${ }^{19-21}$ very little research has been done to evaluate their effectiveness in other chronic lung diseases. Energy conservation is part of the larger discipline of occupational therapy and is often taught in conjunction with the use of gadgets that minimize bending, climbing, and straining, such as bath stools, hand-held showerheads, reaching tools, elastic shoestrings, sock pulls, and button hooks. ${ }^{22,23}$ These techniques are also an integral component of pulmonary rehabilitation programs. ${ }^{24}$ By using these techniques, patients are able to do more with less shortness of breath, allowing them to become more independent. They are also instructed on pacing activities and prioritizing chores because energy conservation is important with daily fluctuation in energy levels.

Although often counterintuitive to patients, training in pacing is not a contradiction to exercise training, as pacing enables greater participation and enjoyment of activities, whereas exercise training conditions patients, allowing them to use pacing throughout a more active and longer lifetime and reverse the cycle of decline. The vast majority of subjects reported continued practice of this intervention for years after pulmonary rehabilitation.

\section{Contact With the Health-Care Provider's Office at the First Sign of an Exacerbation}

COPD exacerbations are often under reported. ${ }^{25,26} \mathrm{Ex}-$ acerbations are associated with subsequent worsening de- pression and health status, as well as higher mortality after hospitalization..$^{27}$ When the health-care provider is notified at the first sign of an exacerbation, there is an opportunity to intervene early with out-patient medical management, such as prednisone, oral antibiotics, nebulizer treatments, and supplemental oxygen. These treatments can prevent an emergency department visit with its attendant costs, invasive therapies, and stress. Conferring with the health-care provider can also trigger a review of symptoms, discuss preventive measures, and generate an action plan for patients for future exacerbations. Participation in maintenance exercise at a pulmonary rehabilitation facility allows pulmonary rehabilitation clinicians to facilitate notification of the health-care provider at the first sign of an exacerbation.

\section{Support Group Participation}

Very few reports have been published on the topic of support groups for patients with chronic respiratory disease. One study in Better Breathers support group members with COPD reported that members demonstrated high levels of self-care that were positively associated with hope and optimism. ${ }^{28}$ A disease-management program delivered in a support group format resulted in subjects with idiopathic pulmonary fibrosis feeling less isolated, more able to put their disease into perspective, and valued by participating in research and helping others. ${ }^{29}$ Support groups have been found to be beneficial in many other patient populations, including diabetes, ${ }^{30}$ cancer, ${ }^{31-33}$ caregivers, ${ }^{34}$ and online groups. ${ }^{35}$ Support groups can take many formats, including peer or professional facilitation, hospital or nonprofit sponsorship, in-person or online formats, education, or skill-focused content. In our sample of subjects who attended pulmonary rehabilitation, subjects consistently reported distance, transportation, and scheduling conflicts as the primary barriers to participation in the follow-up monthly support meetings. Virtual meeting tools, such as internet-based support groups and chat rooms, may be more successful in retaining participation. Several internet-based support groups have been tested with positive results. ${ }^{36}$

Modifiable barriers to support group participation in this sample included lack of awareness and lack of interest, suggesting that improved communication about programs and needs assessments to tailor programs to the specific needs of patients may improve participation. Frequent discussion of the benefits of ongoing participation in the support group after intensive pulmonary rehabilitation can be integrated into the pulmonary rehabilitation sessions. 


\section{Long-Term Benefits of Pulmonary Rehabilitation}

\section{Long-Term Exercise Adherence and Health-Care Utilization}

It is well documented that pulmonary rehabilitation participation decreases health-care utilization for at least $1 \mathrm{y}$ after completion. ${ }^{3,37-40} \mathrm{We}$ sought to extend those findings by analyzing the effect of ongoing exercise after pulmonary rehabilitation. Contrary to the findings of Heppner et al, ${ }^{41}$ who found that subjects who continued to walk regularly after a pulmonary rehabilitation program utilized health care as often as those who did not, our findings show that fewer subjects visited the emergency department or required hospitalization after pulmonary rehabilitation. In the subgroup of subjects who did require an emergency department visit or hospitalization, however, the average number of emergency department visits or hospital days was unchanged after pulmonary rehabilitation. Overall physical activity has been shown to reduce hospital admissions. ${ }^{42}$ Further comparison of our results with others is difficult because health-care utilization outcome measurement is not standardized. ${ }^{43}$

\section{Questionnaire Adherence}

Baseline demographics were quite different between those who completed questionnaires and those who did not. In general, those who did not complete questionnaires suffered from more severe COPD with lower $\mathrm{FEV}_{1}$, had shorter 6-min walk distances, and reported more depressive symptoms. These differences suggest that subjects who completed the surveys were healthier and raise questions about the generalizability of our findings. They also underscore the importance of personal follow-up with patients who are more severely ill and least likely to participate in mailed questionnaires.

There may be a bias between those who complete questionnaires and those who do not. Perhaps patients stop completing questionnaires because they feel worse, ${ }^{13}$ or conversely, they may want to continue to complete questionnaires to document their decline. If patients who are more severely ill discontinue survey completion more frequently or earlier than those who are less severely ill, that bias would lead to results indicating that pulmonary rehabilitation has more long-lasting benefits than in actuality. ${ }^{13}$

\section{Limitations}

The data for this study were self-reported with inconsistent follow-up, which limits the generalizability of our findings to those who complete pulmonary rehabilitation and participate in ongoing data collection. Based on our experience using these quality improvement data for research purposes, it is important for the researcher to be involved in the initial development of the questionnaires and to avoid changes in the questionnaires over time, unless they serve both the needs of the researcher and the clinician. The clinical nature of the data led to imprecise or missing measures of smoking status and non-COPD diagnoses. Systems to follow-up with subjects who do not respond to the surveys should be put in place from the beginning.

\section{Conclusions}

Participation in pulmonary rehabilitation decreases health-care utilization for at least 1 y after participation, 3,37-40 and our findings show that fewer subjects visited the emergency department or required hospitalization after pulmonary rehabilitation over an extended period of time. This effect was especially evident in subjects who continued to exercise regularly after pulmonary rehabilitation. In addition, subjects consistently used non-pharmacologic maintenance techniques (ie, pursed-lip breathing, energy conservation strategies) after pulmonary rehabilitation, and it is possible that the improvement in healthcare utilization was related to those practices.

This study demonstrated the ability of one pulmonary rehabilitation program to accurately monitor extended longterm follow-up after pulmonary rehabilitation. The project was initially designed to document outcomes required for program certification from the American Association of Cardiovascular and Pulmonary Rehabilitation (AACVPR), demonstrate the value of the program to upper management, and provide feedback to pulmonary rehabilitation staff regarding the efficacy of the program. Patients can live for decades after a diagnosis of chronic respiratory disease, yet pulmonary rehabilitation lasts for only 6-12 weeks, making it imperative to quantify the experience of patients after pulmonary rehabilitation so that appropriate interventions to support patients, minimize the impact of the disease, and improve quality of life over the trajectory of their illness can be developed. Implementing this longterm monitoring methodology consistently in pulmonary rehabilitation programs could contribute to evaluation of the comparative effectiveness of various treatment options. We have used our experiences with this long-term monitoring project to participate in an AACVPR committee on the development of the outcomes registry for pulmonary and cardiac rehabilitation programs. The AACVPR registry project has been designed to allow for the collection of long-term quality data and demonstrate a positive impact on patient lives.

\section{ACKNOWLEDGMENTS}

We thank Jenny Bard for assistance with editing the manuscript. 


\section{Long-Term Benefits of Pulmonary Rehabilitation}

\section{REFERENCES}

1. Hodgkin JE, Celli BR, Connors GL. Pulmonary rehabilitation: guidelines to success. Philadelphia: Lippincott; 2000.

2. Nici L, Donner C, Wouters E, Zuwallack R, Ambrosino N, Bourbeau $\mathrm{J}$, et al. American Thoracic Society/European Respiratory Society statement on pulmonary rehabilitation. Am J Respir Crit Care Med 2006;173(12):1390-1413.

3. Griffiths TL, Burr ML, Campbell IA, Lewis-Jenkins V, Mullins J, Shiels K, et al. Results at 1 year of outpatient multidisciplinary pulmonary rehabilitation: a randomised controlled trial. Lancet 2000; 355(9201):362-368.

4. Ries AL, Kaplan RM, Limberg TM, Prewitt LM. Effects of pulmonary rehabilitation on physiologic and psychosocial outcomes in patients with chronic obstructive pulmonary disease. Ann Intern Med 1995;122(11):823-832.

5. Strijbos JH, Postma DS, van Altena R, Gimeno F, Koëter GH. A comparison between an outpatient hospital-based pulmonary rehabilitation program and a home-care pulmonary rehabilitation program in patients with COPD. A follow-up of 18 months. Chest 1996;109(2):366-372.

6. Troosters T, Gosselink R, Decramer M. Short- and long-term effects of outpatient rehabilitation in patients with chronic obstructive pulmonary disease: a randomized trial. Am J Med 2000;109(3):207212

7. Vale F, Reardon JZ, ZuWallack RL. The long-term benefits of outpatient pulmonary rehabilitation on exercise endurance and quality of life. Chest 1993;103(1):42-45.

8. California Pulmonary Rehabilitation Collaborative Group. Effects of pulmonary rehabilitation on dyspnea, quality of life, and healthcare costs in California. J Cardiopulm Rehabil 2004;24(1):52-62.

9. Raskin J, Spiegler P, McCusker C, ZuWallack R, Bernstein M, Busby $\mathrm{J}$, et al. The effect of pulmonary rehabilitation on healthcare utilization in chronic obstructive pulmonary disease: The Northeast Pulmonary Rehabilitation Consortium. J Cardiopulm Rehabil 2006;26(4): 231-236.

10. Rodriguez-Roisin R. Toward a consensus definition for COPD exacerbations. Chest 2000;117(5 Suppl 2):398S-401S.

11. Hartman JE, ten Hacken NH, Boezen HM, de Greef MH. Selfefficacy for physical activity and insight into its benefits are modifiable factors associated with physical activity in people with COPD: a mixed-methods study. J Physiother 2013;59(2):117-124.

12. Donesky D, Nguyen HQ, Paul SM, Carrieri-Kohlman V. The affective dimension of dyspnea improves in a dyspnea self-management program with exercise training. J Pain Symptom Manage 2014;47(4): 757-771.

13. Kesten S, Plautz M, Piquette CA, Habib MP, Niewoehner DE. Premature discontinuation of patients: a potential bias in COPD clinical trials. Eur Respir J 2007;30(5):898-906.

14. Donesky-Cuenco D, Janson S, Neuhaus J, Neilands TB, CarrieriKohlman V. Adherence to a home-walking prescription in patients with chronic obstructive pulmonary disease. Heart Lung 2007;36(5): 348-363.

15. Tiep BL, Burns M, Kao D, Madison R, Herrera J. Pursed lips breathing training using ear oximetry. Chest 1986;90(2):218-221.

16. Nield MA, Soo Hoo GW, Roper JM, Santiago S. Efficacy of pursedlips breathing: a breathing pattern retraining strategy for dyspnea reduction. J Cardiopulm Rehabil Prev 2007;27(4):237-244.

17. Tiep BL. Pursed lips breathing-easing does it. J Cardiopulm Rehabil Prev 2007;27(4):245-246.

18. Giardino ND, Chan L, Borson S. Combined heart rate variability and pulse oximetry biofeedback for chronic obstructive pulmonary disease: preliminary findings. Appl Psychophysiol Biofeedback 2004; 29(2):121-133.
19. Bredin M, Corner J, Krishnasamy M, Plant H, Bailey C, A'Hern R. Multicentre randomised controlled trial of nursing intervention for breathlessness in patients with lung cancer. BMJ 1999;318(7188): 901-904.

20. Connors S, Graham S, Peel T. An evaluation of a physiotherapy led non-pharmacological breathlessness programme for patients with intrathoracic malignancy. Palliat Med 2007;21(4):285-287.

21. Corner J, Plant H, A'Hern R, Bailey C. Non-pharmacological intervention for breathlessness in lung cancer. Palliat Med 1996;10(4): 299-305.

22. Morgan DD, White KM. Occupational therapy interventions for breathlessness at the end of life. Curr Opin Support Palliat Care 2012;6(2):138-143.

23. Velloso M, Jardim JR. Functionality of patients with chronic obstructive pulmonary disease: energy conservation techniques. J Bras Pneumol 2006;32(6):580-586.

24. American Association of Cardiovascular and Pulmonary Rehabilitation. Guidelines for pulmonary rehabilitation programs. Champaign, IL: Human Kinetics; 2011.

25. Langsetmo L, Platt RW, Ernst P, Bourbeau J. Underreporting exacerbation of chronic obstructive pulmonary disease in a longitudinal cohort. Am J Respir Crit Care Med 2008;177(4):396-401.

26. Wilkinson TM, Donaldson GC, Hurst JR, Seemungal TA, Wedzicha JA. Early therapy improves outcomes of exacerbations of chronic obstructive pulmonary disease. Am J Respir Crit Care Med 2004; 169(12):1298-1303.

27. Soler-Cataluña JJ, Martínez-García MA, Román Sánchez P, Salcedo E, Navarro M, Ochando R. Severe acute exacerbations and mortality in patients with chronic obstructive pulmonary disease. Thorax 2005; 60(11):925-931.

28. Alberto J, Joyner B. Hope, optimism, and self-care among Better Breathers Support Group members with chronic obstructive pulmonary disease. Appl Nurs Res 2008;21(4):212-217.

29. Lindell KO, Olshansky E, Song MK, Zullo TG, Gibson KF, Kaminski N, Hoffman LA. Impact of a disease-management program on symptom burden and health-related quality of life in patients with idiopathic pulmonary fibrosis and their care partners. Heart Lung 2010;39(4):304-313.

30. Markowitz JT, Laffel LM. Transitions in care: support group for young adults with type 1 diabetes. Diabet Med 2012;29(4):522-525.

31. Björneklett HG, Rosenblad A, Lindemalm C, Ojutkangas ML, Letocha H, Strang P, Bergkvist L. Long-term follow-up of a randomized study of support group intervention in women with primary breast cancer. J Psychosom Res 2013;74(4):346-353.

32. Sillence E. Giving and receiving peer advice in an online breast cancer support group. Cyberpsychol Behav Soc Netw 2013;16(6): 480-485.

33. Yopp JM, Rosenstein DL. A support group for fathers whose partners died from cancer. Clin J Oncol Nurs 2013;17(2):169-173.

34. Golden MA, Lund DA. Identifying themes regarding the benefits and limitations of caregiver support group conversations. J Gerontol Soc Work 2009;52(2):154-170.

35. Hu X, Bell RA, Kravitz RL, Orrange S. The prepared patient: information seeking of online support group members before their medical appointments. J Health Commun 2012;17(8):960-978

36. Richardson CR, Buis LR, Janney AW, Goodrich DE, Sen A, Hess ML, et al. An online community improves adherence in an internetmediated walking program. Part 1: results of a randomized controlled trial. J Med Internet Res 2010;12(4):e71.

37. Foglio K, Bianchi L, Ambrosino N. Is it really useful to repeat outpatient pulmonary rehabilitation programs in patients with chronic airway obstruction? A 2-year controlled study. Chest 2001;119(6): 1696-1704. 


\section{Long-Term Benefits of Pulmonary Rehabilitation}

38. Hui KP, Hewitt AB. A simple pulmonary rehabilitation program improves health outcomes and reduces hospital utilization in patients with COPD. Chest 2003;124(1):94-97.

39. Ries AL, Bauldoff GS, Carlin BW, Casaburi R, Emery CF, Mahler DA, et al. Pulmonary Rehabilitation: Joint ACCP/AACVPR EvidenceBased Clinical Practice Guidelines. Chest 2007;131(5 Suppl):4S-42S.

40. Rubí M, Renom F, Ramis F, Medinas M, Centeno MJ, Górriz M, et al. Effectiveness of pulmonary rehabilitation in reducing health resources use in chronic obstructive pulmonary disease. Arch Phys Med Rehabil 2010;91(3):364-368.
41. Heppner PS, Morgan C, Kaplan RM, Ries AL. Regular walking and long-term maintenance of outcomes after pulmonary rehabilitation. J Cardiopulm Rehabil 2006;26(1):44-53.

42. Garcia-Aymerich J, Lange P, Benet M, Schnohr P, Antó JM. Regular physical activity reduces hospital admission and mortality in chronic obstructive pulmonary disease: a population based cohort study. Tho$\operatorname{rax} 2006 ; 61(9): 772-778$.

43. Ochmann U, Jörres RA, Nowak D. Long-term efficacy of pulmonary rehabilitation: a state-of-the-art review. J Cardiopulm Rehabil Prev 2012;32(3):117-126 